\title{
METODOLOGIA PARA A IMPLANTAÇÃO DO SISTEMA DE GERENCIAMENTO DIÁRIO: PROCESSO DE FABRICAÇÃO DE TUBOS DE COBRE DE SISTEMAS DE REFRIGERAÇÃO DE AR-CONDICIONADO RESIDENCIAL
}

\author{
METHODOLOGY FOR THE IMPLEMENTATION OF THE DAILY \\ MANAGEMENT SYSTEM: COPPER TUBE MANUFACTURING PROCESS \\ RESIDENTIAL AIR CONDITIONING REFRIGERATION SYSTEMS
}

\author{
Mychellangelo dos Santos Soares ${ }^{1}$; Tirso Lorenzo Reyes Carvajal ${ }^{2}$ \\ ${ }^{1}$ Universidade Federal do Pará - UFPA - Pará - Brasil \\ mychellangelo@yahoo.com.br \\ ${ }^{2}$ Instituto de Tecnologia Galileo da Amazônia - ITEGAM - Manaus - Brasil \\ tirsolrca@gmail.com
}

\begin{abstract}
Resumo
O presente trabalho apresenta uma metodologia para a implantação do sistema de gerenciamento diário no processo de fabricação de tubos de cobre de sistemas de refrigeração de ar-condicionado residencial. A origem que motivou o desenvolvimento deste trabalho decorre da observação por parte do pesquisador o qual vislumbrou que era necessário sistematizar as ações com a finalidade de orientar qualquer profissional da empresa através de uma ferramenta de gestão visual nivelando os diferentes níveis de informações referentes ao processo de fabricação. O trabalho foi realizado a partir de uma fundamentação teórica que serviu de base para o desenvolvimento empírico no campo. $O$ objetivo principal do trabalho é apresentar o modelo de ferramenta, para posterior implantação. No entanto, a partir das análises empíricas, acredita-se que vários benefícios podem ser obtidos com sua implantação, sendo estes apresentados no trabalho, dos quais se destaca o gerenciamento das atividades consideradas críticas para o alcance dos objetivos estratégicos da empresa. Finalmente conclui-se que, a metodologia desenvolvida facilitará o trabalho daqueles pesquisadores ou profissionais que por ventura tem o interesse de utilizar a ferramenta DMS.
\end{abstract}

Palavras-chave: sistema de gestão; sistema de gerenciamento diário; administração da produção.

\section{Introdução}

O cenário atual que as empresas estão enfrentando é um ambiente competitivo e de rápidas mudanças; apenas as empresas com maior capacidade de adaptação gerencial estarão aptas a se manterem no mercado, buscando maior competitividade, padronização, dinamismo, redução de desperdícios, desenvolvimento tecnológico, expansão e resultados. O gerenciamento diário é conduzido para proporcionar a melhoria contínua na empresa, manutenção de operações, como cumprimento dos padrões e melhorias, com alteração dos padrões existentes e atuação na causa dos 
desvios. Implantar o gerenciamento diário exige o comprometimento e participação dos diferentes níveis hierárquico: Níveis estratégico, tático e operacional bem como a padronização de vários métodos e ferramentas para a rotina se manter sustentável. No presente trabalho vamos abordar o projeto de criação e desenvolvimento do gerenciamento diário no, processo de fabricação de tubos, implantado dentro de uma linha piloto numa empresa de grande porte. Os problemas motivadores do trabalho na empresa foram a dificuldade em gestão da equipe, controle do tempo, rotina desvirtuada, e algumas ferramentas disponíveis sem uso. O gerenciamento diário é um processo que visa garantir e conduzir o cumprimento das metas individuais dos colaboradores, diariamente, garantindo o resultado da organização. Portanto o objetivo desse trabalho é implantar uma sistemática de gerenciamento diário para melhoria no processo de fabricação de tubos.

\section{Metodologia}

Quanto aos objetivos, esta pesquisa classifica-se como uma pesquisa descritiva, já que irá partir da observação e análise para descrever uma implantação e execução de uma ferramenta gerencial, sem influência do pesquisador sobre o mesmo. Ainda, a pesquisa será de caráter exploratório, já que visa proporcionar maior familiaridade com o problema com vistas a torná-lo explícito ou a construir hipóteses. Quanto aos procedimentos técnicos, trata-se de uma pesquisa documental, bibliográfica e de estudo de caso. A revisão bibliográfica realizada está embasada em materiais já existentes na literatura, constituído principalmente de livros, artigos, teses e monografias, relacionados a assuntos ligados ao Sistema Toyota de Produção, e Daily Management System.

\section{Gestão da Produção e Operações}

Na ótica de Moreira (1996), a administração da produção é fundamental para manter a competitividade das organizações. Estas desenvolvem os processos produtivos para atingir seus objetivos planejados com coerência, alinhando recursos como pessoas, matéria prima, equipamentos e capital. Portanto, a administração da produção está voltada à companhia, à direção, ao controle e ao planejamento das operações produtivas. Fazendo que estes estejam em harmonia com os objetivos da empresa. Corroborando, Correa e Correa (2006) destacam que a gestão de operações realiza o gerenciamento estratégico dos recursos escassos, agregando valores aos produtos finais.Com a interação entre gestão da produção e processos, buscam atender as necessidades e desejos dos clientes. Não obstante, Shingo (1996) considera a produção como um sistema funcional de processos e operações. Por meio dos processos são transformadas matérias primas em produtos, ou seja, as ações das operações que realizam estas transformações. 
Esses conceitos fundamentais e sua relação devem ser compreendidos a fim da concretização das melhorias efetivas na produção. Desse modo, para atingir satisfação na gestão da produção e operações, faz-se necessário o entendimento das ferramentas adequadas para cada empresa, as quais possam fazem com que elas alcancem os resultados esperados. É fundamental para as organizações compreendam esse sistema, uma vez que almejam a excelência nos processos produtivos.

\section{As 4 Regras Em Uso Do Sistema Toyota De Produção}

No artigo "Decodificando o DNA do Sistema Toyota de Produção" Steven Spear e H. Kent Bowen (SPEAR \& BOWEN, 1999) abordam o problema de porque algumas empresas conseguem colher o sucesso de implantar o TPS e outras se frustram pela incapacidade de reproduzir o desempenho da Toyota. A questão da cultura japonesa argumento tão utilizado para refutar a implantação do TPS em outros países, é minimizada pelo acompanhamento dos sucessos de implantação nos E.U.A. e pelo fracasso de algumas empresas no Japão.

Segundo os autores, a principal questão é a diferença entre a implantação de ferramentas e práticas do TPS e o sistema propriamente dito. Existe um paradoxo a ser desvendado: "a especificação rígida é a atividade fundamental que possibilita a flexibilidade e a criatividade". A chave é compreender que o Sistema Toyota de Produção cria uma comunidade de cientistas. Desta forma, sempre que uma especificação é estabelecida, uma série de hipóteses podem ser testadas através do método científico. O engajamento dos funcionários da empresa neste tipo de experimentação é o marco de uma organização que aprende. Um ponto crucial na proposta dos autores é de que o método científico não é imposto pela empresa, mas emerge da estrutura montada pelo TPS. Em assim sendo foram identificadas 4 regras que definem esta estrutura:

$\checkmark \quad 1^{\text {a }}$ regra - Todos os trabalhos devem ser minuciosamente especificados em termos de conteúdo, sequencia, tempo e resultado.

$\checkmark \quad 2^{\mathrm{a}}$ regra - Todas as conexões cliente-fornecedor devem ser diretas e binárias (sim/não) para enviar solicitações e receber respostas.

$\checkmark \quad 3^{\mathrm{a}}$ regra - Todos os fluxos dos produtos e serviços devem ser simples e diretos.

$\checkmark \quad 4^{\mathrm{a}}$ regra - Todas as melhorias precisam ser feitas continuamente e em conformidade com o método científico, sob a orientação de um líder e no nível mais baixo da organização.

Intrinsecamente ligado as 4 regras em uso (termo utilizado para diferenciar das normas pregadas na parede) está o modo como a melhoria deve acontecer. Para o TPS, cada melhoria deve nascer do trabalho de uma equipe que formulou e testou hipóteses e não fruto do esforço aleatório e individual, desconectado dos requisitos de negócio da empresa. O foco no modo como a resolução de problemas acontece é tão forte que o TPS é conhecido como um sistema que resolve problemas. 


\section{Estratégia do Negócio}

Conforme Quinn apud Ghobad (2003), estratégia é como um padrão ou plano que integra as principais metas, políticas e sequencia de ações de uma organização em um todo coerente. Portanto, uma estratégia bem formulada ajuda com que os recursos de uma organização sejam ordenados e alocados, para uma postura singular e viável, com base em suas competências e deficiências internas relativas, mudanças antecipadas no ambiente e eventual providência realizadas por concorrentes.

A administração estratégica é, em um contexto geral, a forma como é visto o processo como um todo da estratégia, e conforme Wright apud Ghobad (2003), em sentido mais amplo, ela consiste em decisões e ações administrativas que auxiliam a assegurar que a organização formula e mantém adaptações benéficas com seu ambiente. Formular estratégias envolve determinar cursos de ação apropriados para alcançar os objetivos. Isso inclui atividades como análise, planejamento e seleção de estratégias que aumentem as chances de que os objetivos de uma organização possam ser alcançados.

Após a definição das estratégias, a empresa deve elaborar planos de ação, com as atividades necessárias para por em prática tais decisões, considerando para isto, todas as análises de ambiente externo e interno. No entanto, para atingir seus objetivos, uma organização deve não somente formular, mas também implementar efetivamente suas estratégias, já que se uma dessas tarefas for malfeita, é provável que o resultado seja uma falha na estratégia global.

Segundo Thompson et al apud Ghobad (2003), a função de implementação da estratégia consiste em ver o que é necessário para fazer uma estratégia funcionar e atingir o desempenho programado dentro do prazo estipulado. Assim, a implementação das estratégias consiste em colocá-las em ação. Para Kotler (2006) ${ }^{[23]}$, à medida que a empresa implementa sua estratégia, ela precisa acompanhar os resultados e monitorar os novos acontecimentos nos ambientes interno e externo. O Planejamento Estratégico de unidades de negócio consiste em etapas, conforme vistas na figura abaixo: 
Figura 1: O Processo de Planejamento estratégico de negócios

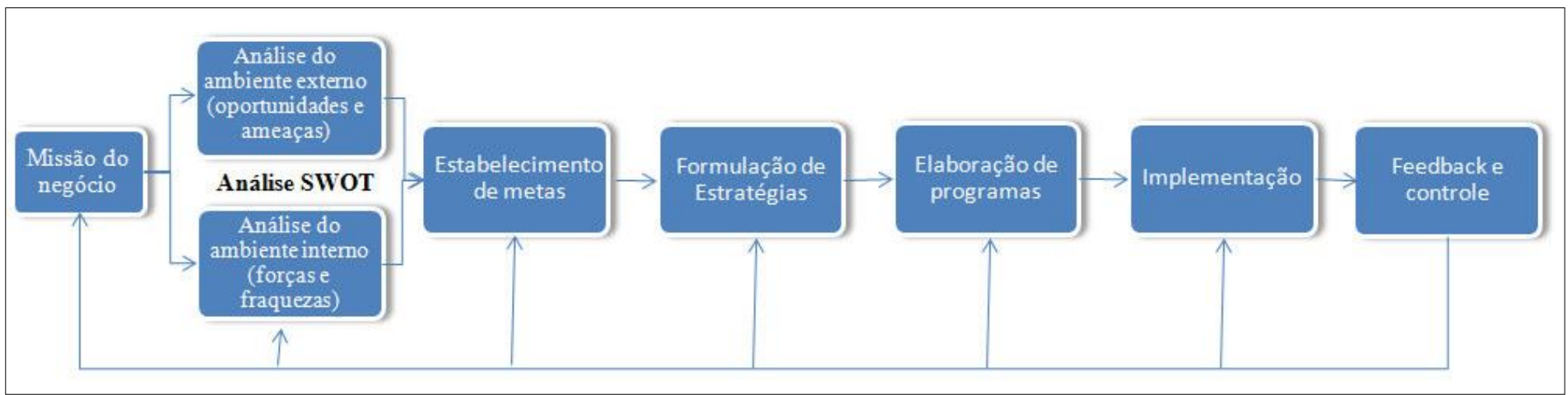

Fonte: Kotler et al (2006)

O resultado final do processo de controle é a informação e por isso a empresa deve estabelecer um sistema de informações que permita a constante efetiva avaliação dos objetivos, metas e estratégias, sendo a seqüência natural para a continuação do ciclo estratégico da organização. A partir das estratégias definidas no Planejamento Estratégico, estas são desdobradas no Plano Operacional das áreas, responsáveis por sua implementação, tendo por objetivo a utilização eficientemente os recursos disponíveis.

Nesta etapa devem ser tomadas as decisões de médio prazo. Assim sendo, para que todos os níveis conheçam as estratégias (objetivos) e metas do Negócio, além de entender seu papel e sua responsabilidade para o atingimento das mesmas, pode-se utilizar a ferramenta de controle visual DMS.

\section{Controle visual e trabalho padronizado}

Segundo Liker (2005) ${ }^{]}$, a tarefa mais crítica quando implementamos a padronização é achar o meio termo entre prover aos funcionários rígidos procedimentos a serem seguidos e ao mesmo tempo dar a liberdade para que eles possam inovar e ser criativos para contribuir com os objetivos de custo, qualidade e entrega.

O autor ressalta que os primeiros padrões e instruções devem ser específicos o suficiente para serem guias úteis, e ainda generalistas o suficiente para permitir a flexibilidade e o fácil entendimento para qualquer pessoa que irá usá-lo. É importante utilizar as idéias dos próprios funcionários para aprimorar as instruções de trabalho, dando a oportunidade para que eles possam contribuir para a melhoria contínua no processo.

As pessoas desejam poder assumir a responsabilidade por seus próprios recursos. Querem sentir que estão dando uma contribuição pessoal para algo importante. É assim que se consegue a verdadeira motivação e a verdadeira administração participativa. As variações, erros ou desvios devem ser corrigidos para que as operações sejam normalizadas. 
A padronização visa manter o desempenho dentro do nível pré-estabelecido e também assegurar que tudo seja feito exatamente de acordo com o que se pretendia fazer (LIKER, 2005).

Segundo Liker (2005), O controle visual é qualquer meio de comunicação usado no ambiente de trabalho que mostra rapidamente como o trabalho deve ser ou está desviado do padrão ou meta estabelecida. Também ajuda os funcionários a fazer o trabalho de forma correta e igual ao procedimento padrão a ser seguido no processo de trabalho. Para Liker (2005), os controles visuais também incluem os desvios entre a meta e o realizado exibidos sob forma gráfica, onde são fixados em local publico e de fácil visualização.

A grande questão a ser observada é possibilidade de andar pela empresa e reconhecer que o padrão de trabalho, procedimentos e metas estão sendo seguidos e alcançados. $\mathrm{O}$ autor ressalta que nas linhas de produção, o uso dos controles visuais, ou gerenciamento pela visão, torna-se obrigatório. Portanto, é necessário estabelecer um processo padronizado pelos quais as condições atuais se tornam rapidamente visíveis no local de trabalho permitindo que todos os funcionários visualizem imediatamente a situação normal ou anormal, bem como reconheçam a situação e tomem ações para retornar à condição padrão.

\section{Daily Management System (DMS)}

Sistema de Gerenciamento Diário, ou do inglês Daily Management System, é um sistema que envolve todas as camadas da empresa, desde o time de gerenciamento até os funcionários do nível operacional, na participação das melhorias dos requisitos de negócio, implementadas através de um método padronizado.

Entretanto, para que as melhorias dos requisitos de negócio ocorram, deve-se haver um alinhamento claro das metas por todos, baseado na estratégia de negócio escolhida. Para suportar estas metas, a execução das atividades diárias do nível operacional deve ser realizada por meio de métodos padronizados.

Uma vez claro o requisito de negócio para melhorias de uma determinada área, se faz necessário o detalhamento de observações no nível operacional, para haver um verdadeiro entendimento, e ainda, a documentação da situação atual. Desta forma é possível determinar as disponibilidades operacionais e identificar a capacidade de produção, permitindo, portanto, que desperdícios que existam dentro do sistema, sejam claramente identificados.

Entretanto, é essencial que todos os empregados participem da melhoria dos negócios por meio de uma ativa busca de solução de problemas, já que perdas não permitem à organização alcançar a produção desejada, como originalmente definida como um padrão de expectativa, assim qualquer pessoa é capaz de entender que isto é um problema. 
Assim, se faz necessário uma compreensão compartilhada de todos do grupo, desde o nível operacional até o gerente, sobre as metas, padrões e problemas.

De acordo com Dennis (2008), Michael Greif definiu um triângulo de gerenciamento visual, no qual todos da equipe deveriam enxergar conhecer e agir como um grupo, conforme a figura abaixo:

Figura 2: A Fábrica Visual

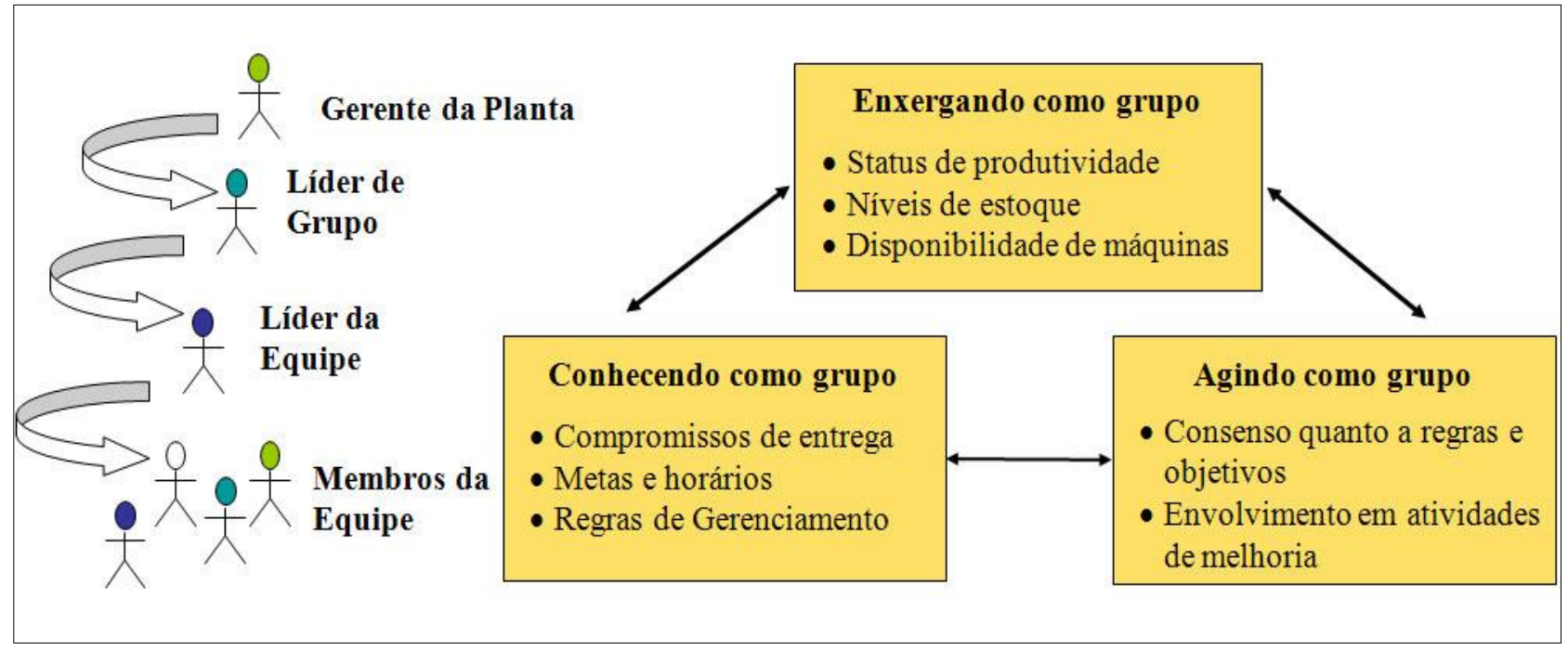

Fonte: Adaptado de Dennis (2008)

Para Henderson et al (1999), como a exposição da informação é um item crítico da fábrica visual, esta deve estar exposta em pelo menos dois níveis: no de desempenho individual da área de trabalho ou do departamento e no de desempenho geral da planta.

Com o requisito do negócio e os métodos de trabalho padronizados claramente definidos, a essência do DMS pode começar a ser exercitada no nível operacional da organização.

Entretanto, o pessoal do nível operacional deverá empenhar-se na demonstração, de maneira visual, dos resultados contra o padrão para que e ações pré-especificadas sejam acionadas quando um problema for identificado. Isto assegura, então, que os empregados de fato conheçam as expectativas de produção e iniciem a solução adequada dos problemas, através da busca de suas causas raízes e, conseqüentemente, empenhem-se constantemente para melhorar os resultados do negócio.

Uma maneira para que, através do DMS, esta melhoria dos resultados ocorra, é o gerenciamento, que deve ter um claro e definido processo de supervisão, assegurando que os trabalhadores sejam monitorados e assistidos no esforço de atingir a produção padrão pré-especificada.

Esta supervisão se faz necessária, já que a falta de participação pela gerência seria um claro sinal de que o processo de melhoria definido não é importante e digno da atenção da organização. Desta forma, o processo de check deve tomar a forma de, no mínimo, interação diária com os resultados de desempenho, para assegurar que o pessoal do nível operacional obtenha os recursos necessários que os permitam continuar melhorando a produção padrão, que direciona os negócios. 
Esta melhoria dos negócios é conduzida através da solução de problemas, já que somente reconhecer um problema por meio da identificação que um padrão pré-especificado não foi atingido, não é suficiente. Assim, conhecer claramente quando um problema ocorreu é essencial, mas é apenas o primeiro passo para a melhoria, já que não procurar a causa do problema tornará o DMS inútil.

Desta maneira, o DMS deve ter um claro e ativo componente de solução de problemas embutido em sua estrutura, que precisará estar claro para todos os envolvidos.

Além disso, devem estar claros os problemas que surgiram, os que estão sendo trabalhados e os que já foram solucionados. Sendo que estes últimos devem estar ligados às melhorias da produção padrão e estas devem ser quantificadas para que qualquer pessoa possa entender seu progresso.

\section{Estrutura Do Daily Management System}

O DMS é montado sob a forma de um quadro visual na área onde seu acompanhamento é realizado, de forma que todos possam enxergar e gerenciar o andamento da atividade. A figura abaixo mostra como um quadro DMS pode ser estruturado, levando-se em consideração os itens necessários para o seu acompanhamento.

Figura 3: Modelo de Quadro de DMS

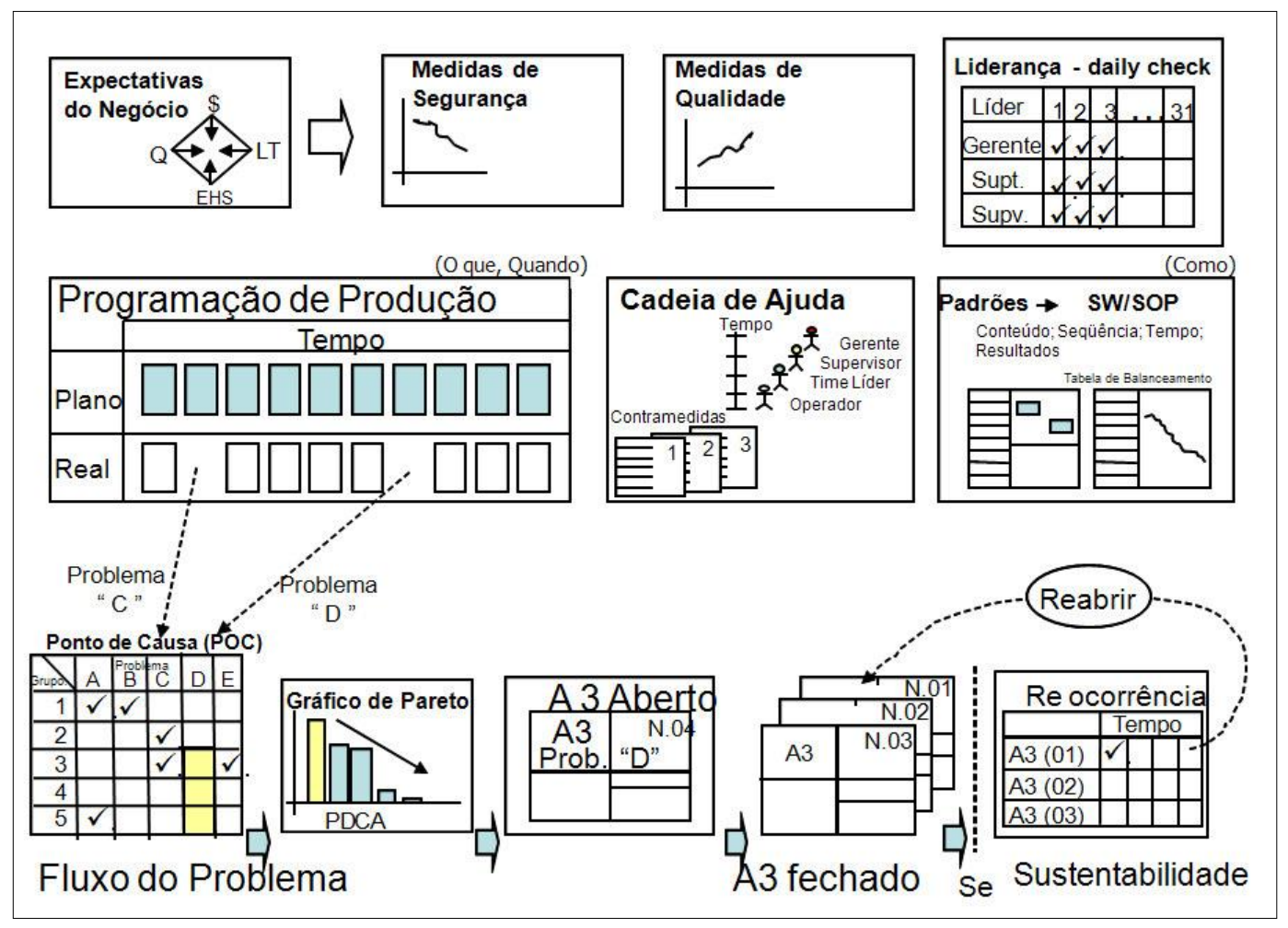

Fonte: Alcoa (2008)

Por meio da figura é possível observar que, definido os requisitos do negócio, é necessário vinculá-los com indicadores específicos, que direcionam o foco em ações importantes e em resultados, desdobrando as estratégias e estes indicadores para todos os níveis, através de controles visuais, para poder então, gerenciar a programação da produção. 
Desta forma, as atividades devem seguir o ritmo da produção, baseado na demanda do mercado, ou seja, o tempo de ciclo da atividade, que é o intervalo de tempo entre unidades sucessivas que saem de um processo, deve ser menor ou igual ao takt time, que é o tempo máximo necessário para fornecimento de uma peça, conforme a demanda do cliente. Assim, os projetos, operações e processos, devem ser orientados, utilizando-se para isto as quatro regras em uso (RIU), de maneira a especificar a forma de realização das atividades, através de uma conexão simples e binária, contando com um fluxo simplificado durante o processo de fabricação e, buscando a melhoria constantemente.

Ainda, é importante haver um formulário, daily check, onde as lideranças registram o tipo de visita feita à frente de serviço, já que a demonstração de comprometimento da liderança com a sistemática aplicada é imprescindível para seu funcionamento.

Como forma de garantir que o método mais eficaz de execução da atividade seja seguido, dados os requisitos de segurança, ergonomia e meio ambiente, qualidade e volume de produção, este deve ser padronizado e estar visível.

De acordo com Dennis (2008), mesmo os melhores processos estão repletos de perdas, portanto, o trabalho padronizado se modifica constantemente, em busca da melhoria. Uma vez detectado um problema que possa vir a comprometer a programação da produção, esse deve ser arduamente combatido.

A lógica deste princípio envolve identificação, contramedida imediata para a retomada do fluxo, análise da causa e plano de ação para eliminação da causa.

Portanto, após a identificação do problema, uma cadeia de ajuda é contatada, devendo essa, através da adoção de contramedidas que irão atenuar os efeitos deste problema, re-conectar o processo e o fluxo da atividade.

De acordo com Kamada (2008) , a cadeia de ajuda é uma rotina de interação e envolvimento entre as pessoas, que se inicia pelo operador da atividade e envolve as lideranças imediatas e os responsáveis de todas as áreas de apoio, e tem o objetivo de resolver um problema, quando esse surge, e eliminar as instabilidades do processo.

Assim, os pontos de causa dos problemas identificados são quantificados em uma tabela, para que sejam estratificados em um diagrama de Pareto e posteriormente, identificados os mais críticos, que necessitam ser primeiramente tratados.

Para isto, aplica-se a regra $80 / 20$, concentrando $80 \%$ da energia sobre os $20 \%$ de problemas que produziram $80 \%$ do benefício total. O processo de solução de problemas é feito através da ferramenta "A3" de solução de problemas, assim denominado por descrever a apresentação destas atividades em uma única página de papel tamanho "A3" (27,5 cm X 42,5 cm). 
Conforme Liker et al (2007), o desenvolvimento do "A3" deve seguir a sequencia mostrada abaixo: 1. Desenvolvimento de uma completa compreensão da situação presente e definição do problema;

2. Realização de uma análise completa da raiz do problema;

3. Total consideração de soluções alternativas enquanto se constrói o consenso;

4. Planejar - Fazer - Verificar - Agir (PDCA);

5. Reflexão e aprendizagem com o processo.

A etapa 4 citada acima, referente ao ciclo PDCA de solução de problemas pode ser melhor analisado através da figura abaixo:

Figura 4: Ciclo PDCA de Solução de Problema

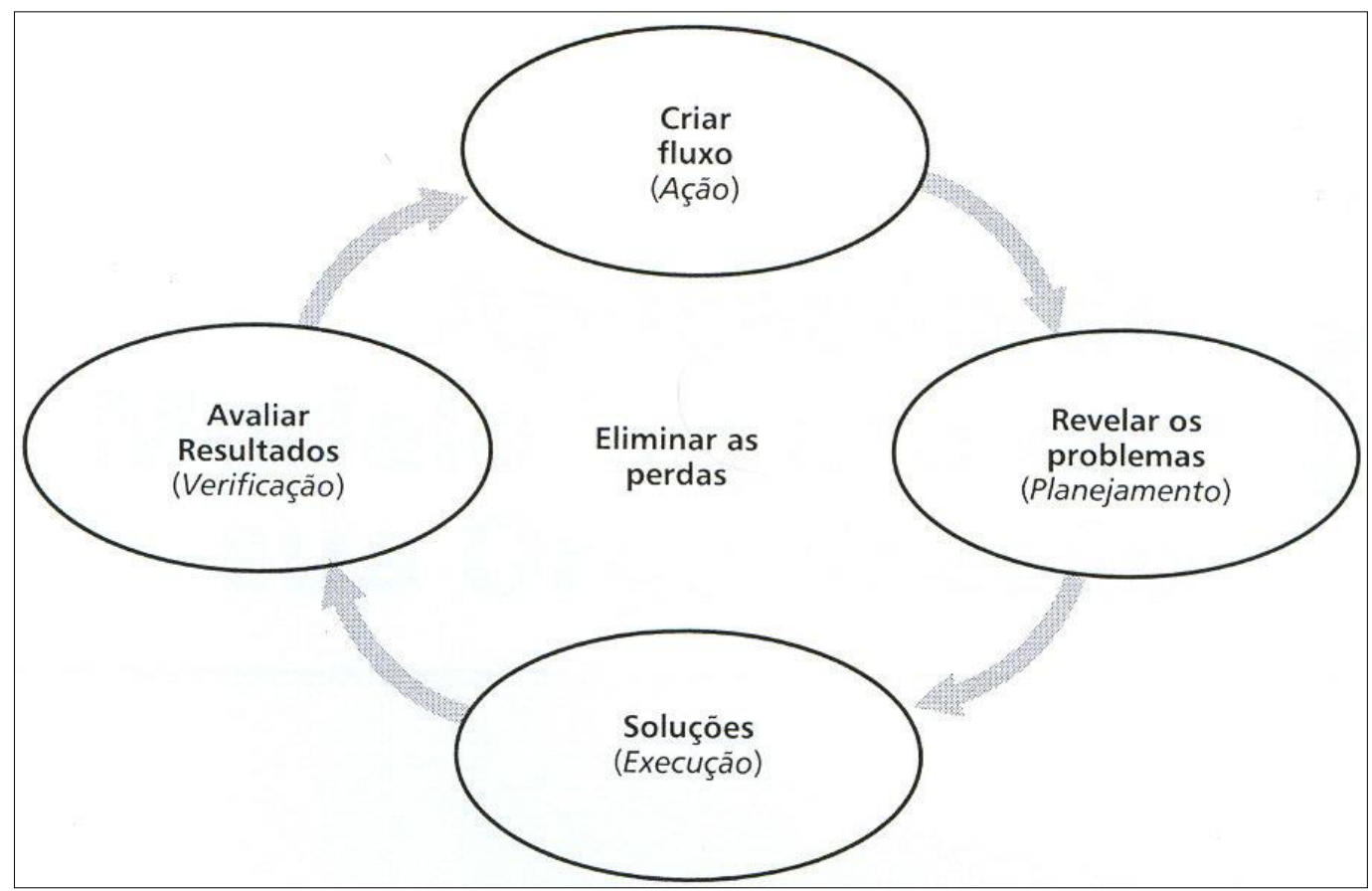

Fonte : Do Autor 


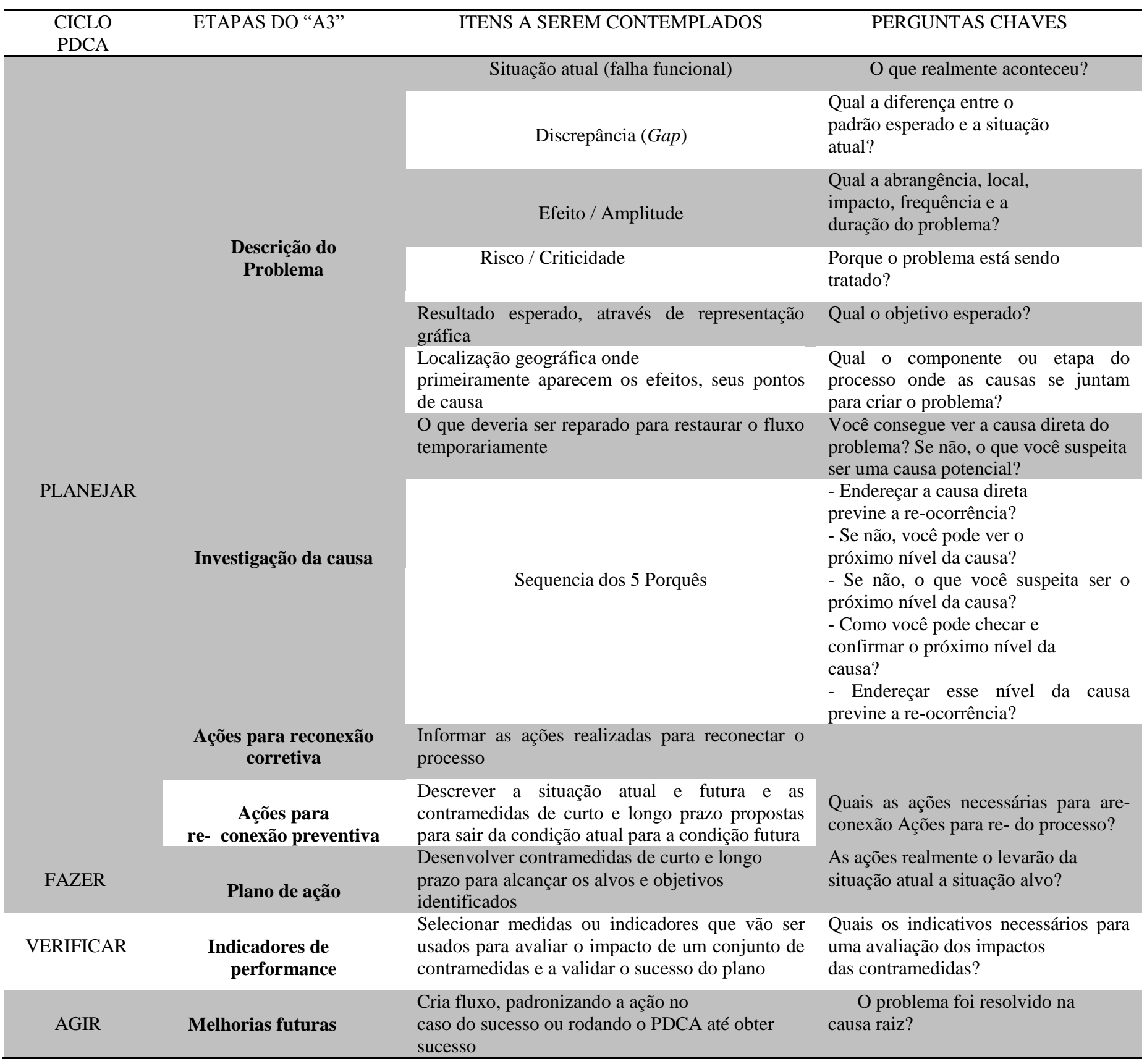

Fonte: Pesquisa direta

Após a resolução do problema através do "A3", este deve ser "fechado", ou seja, arquivado para ser usado no caso de sua re-ocorrência. No entanto, todas estas re-ocorrências devem ser registradas em um quadro para quantificação e priorização das ações corretivas, já que indicam que a resolução do problema pode não ter ocorrido na sua causa raiz ou este pode ter múltiplas causas. 


\section{Atividades essenciais do Daily Management System}

As atividades núcleo do DMS podem ser esboçadas, resumidamente, da seguinte maneira: 1. Compreender claramente a importância do fluxo dos negócios, o suficiente para escolher atividades de melhoria que agregarão valor. Ser capaz de relatar o trabalho que pessoas fazem diariamente para a melhoria necessária do conhecimento do negócio;

2. Para cada atividade-chave desenvolver um padrão e comunicá-la da maneira mais visível possível;

3. Usar desvios do padrão para identificar e coletar dados sobre problemas;

4. Selecionar problemas para se trabalhar;

5. Desenvolver um “A3” de solução de problema para cada problema escolhido;

6. Solucionar problemas pela raiz empregando esquemas de solução como

5 porquês e Diagrama de "Espinha de Peixe". Testar aqueles problemas que são resolvidos pela raiz buscando sua re-ocorrência, já que muitos problemas têm múltiplas causas.

7. Checar se a solução do problema está mudando o indicador chave que agrega valor ao negócio. Medir o número de problemas resolvidos pela raiz e comparar a real mudança contra o valor esperado de cada solução.

8. Ter um claro e freqüente processo de supervisão (processo de check) envolvendo todas as camadas da gerência.

\section{Implantação do Daily Management System}

A implantação da ferramenta DMS deve ser coordenada por uma equipe multidisciplinar, composta por representantes de todas as áreas da unidade, os quais serão os responsáveis por “desdobrar" as decisões para todos os empregados de suas respectivas áreas. Esta equipe é denominada de Equipe Líder, sendo definida pela alta direção, é a responsável pelo apoio às demais áreas da Unidade. A equipe líder é responsável por coordenar a implantação do sistema de gestão o Planejamento Estratégico da Unidade e Plano Operacional das áreas, além de realizar análises críticas de indicadores, ministrar treinamentos, coordenar auto auditorias de excelência operacional, e desenvolver processos de melhoria contínua. Assim, após definidos os responsáveis pela implantação do DMS, par te-se para a preparação do plano de implantação.

Para o desenvolvimento deste plano, deve-se tomar como base o conceito do ciclo PDCA como método para identificar e controlar, de forma lógica, as etapas da implantação, a criação de controles com foco na melhoria dos processos, além de evitar erros lógicos de análise 


\section{Execução do Daily Management System}

1. Posterior ao desenvolvimento do plano de implantação do DMS é importante que se planeje sua execução. Como este trabalho está focado na produção de tubos de cobre, a empresa utiliza o Mapa Fluxo de Valor para identificar, de forma visual, o fluxo de produtos, materiais e informações, desde o pedido do cliente até a entrega do produto final, esta ferramenta poderá servir de base para a determinação das etapas críticas do processo.

2. Tendo os processos críticos definidos, para garantir sua entrega, deve se gerenciar o planejamento da produção e solucionar os problemas que possam impedir seu alcance, executando o DMS em cada um destes processos.

3. Assim, para planejar a execução do DMS, o conceito do ciclo PDCA também poderá servir como método, conforme pode ser vis to por meio da figura abaixo:

Figura 5: PDCA de Execução do DMS

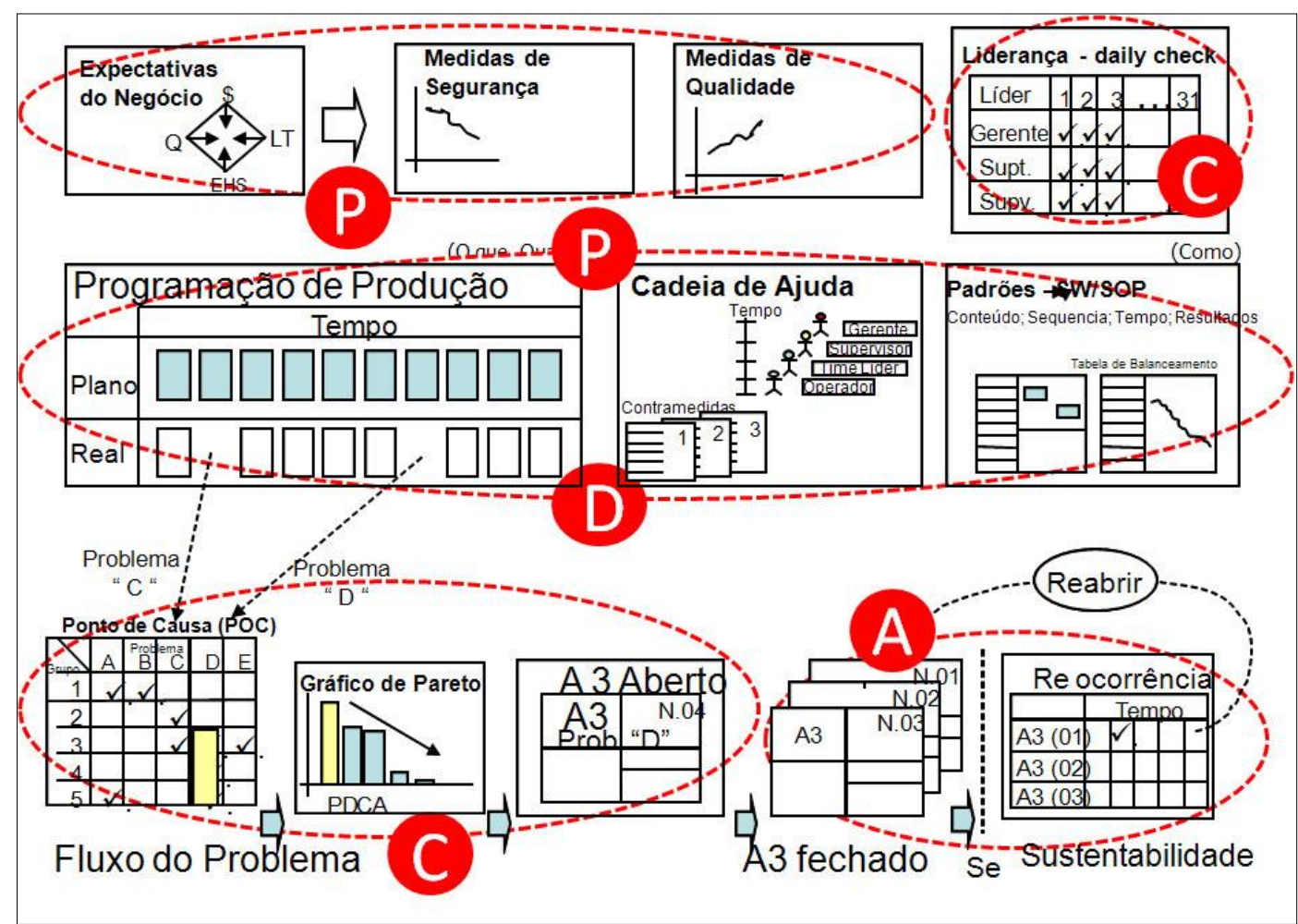

Fonte: Adaptado de Alcoa (2008)

Nota-se na figura acima, que na execução do DMS, o planejamento (Plan) se inicia com a definição das expectativas do negócio que irão servir como indicadores de desempenho.

Estes indicadores são dispostos visualmente no quadro, em forma de gráficos, fazendo com que os funcionários conheçam o desempenho padrão necessário para o alcance de suas metas e 
consequentemente dos objetivos do negócio. O indicador de entrega é utilizado para realizar o acompanhamento da entrega aos clientes. Desta forma, para que a atividade obtenha seu desempenho padrão, esta deve garantir $100 \%$ da entrega a seu cliente, seja ele interno ou externo.

Tendo-se como base o processo, onde as pessoas sustentam o sistema, a segurança não deve ser deixada em segundo plano em detrimento da produção.

Desta forma, não deve haver incidentes, tanto aos funcionários quanto ao meio ambiente na realização da atividade e, portanto, o indicador de EHS deve ter $0 \%$ de ocorrência de incidentes.

Através do vetor qualidade, a empresa efetua o acompanhamento de retrabalhos durante a execução das atividades, já que este é considerado uma perda e deve, portanto, ser eliminado.

Já o indicador de custo, mede o valor adicional para a realização da atividade, sendo assim, este valor não deve ultrapassar o estabelecido para sua execução.

Ainda na etapa de planejamento são determinados o takt time e o tempo de ciclo para realização da atividade. A partir desta definição o plano de produção necessário para o atendimento da demanda do cliente é definido, pré-especificando tempos e necessidade de produção para o atingimento das metas.

Tendo como objetivo garantir que o método mais eficaz de execução da atividade seja seguido, dados os requisitos de segurança, ergonomia e meio ambiente, qualidade e volume de produção, este deve ser planejado e padronizado e estar disposto visivelmente no quadro.

Este padrão poderá ser feito por meio de prática padrão, fluxo ou procedimentos operacionais. A definição da cadeia de ajuda é uma atividade realizada dentro do planejamento da execução do DMS, devendo esta promover a interação e o envolvimento entre as pessoas para a solução de um problema, quando este surgir.

Esta cadeia é iniciada pelo operador da produção e envolve as lideranças imediatas e os responsáveis de todas as áreas de apoio, conforme a figura abaixo:

Figura 6: Cadeia de Ajuda

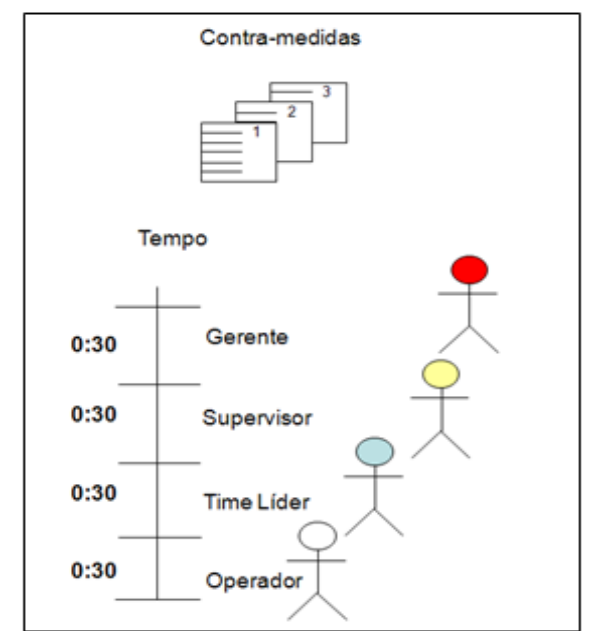

Fonte: Adaptado Pelo Autor 
Nesta cadeia de ajuda é necessário definir o tempo em que cada nível deverá ser acionado, de maneira que takt time determinado seja atendido. Além do tempo, as contramedidas necessárias para a re-conexão do fluxo devem ser apontadas. Após a etapa de planejamento, inicia-se a etapa de fazer $(D o)$, com execução da atividade, que será realizada conforme o padrão definido anteriormente.

Para verificar se a execução da atividade está de acordo com a programação, etapa Check, a liderança deve estar presente no local onde a atividade é realizada (Genchi Genbutsu), para assim, obter um completo entendimento de sua execução. Esta presença deve ser registrada em formulários, denominados daily check, contendo o tipo de visita feita ao local.

Desta forma, através do quadro planejado $\mathrm{x}$ realizado, mostrado a seguir, pode-se acompanhar a execução da produção com a programação, acionando, sempre que problemas forem detectados, a cadeia de ajuda e aplicando as contramedidas para que o fluxo produtivo seja reconectado. Assim que o fluxo produtivo for restabelecido, todos os pontos de causa dos problemas encontrados são estratificados em um quadro de acordo com sua freqüência.

Desta forma é possível desenvolver um gráfico de Pareto para determinar quais os principais problemas. A solução destes problemas é realizada por meio do "A3" de solução de problemas, que deve conter o tema e o contexto do problema, a condição atual que o produziu, uma análise de sua causa raiz, o estado futuro, ou condição alvo que se deseja, e ainda, o plano de implantação, os indicadores de desempenho e as melhorias futuras.

\section{Conclusões e Recomendações}

O propósito desta pesquisa foi registrar uma metodologia para a implantação do sistema de gerenciamento diário no processo produtivo de tudo de cobre. O estudo foi desenvolvido a partir de investigações empíricas, efetuadas durante a elaboração do plano de implantação. Para o alcance do objetivo proposto, seguiu-se um processo de investigação acadêmico científico em três etapas: a fundamentação teórica referente a Sistema Toyota de Produção, Estratégia de Negócio e Daily Management System, definição dos procedimentos metodológicos, elaboração do estudo de caso na empresa, ou seja, na fábrica PIM e, a análise da implantação e descrição da execução do Daily Management System. Finalmente, apresentou-se em destaque alguns dos prováveis benefícios que podem ser obtidos com o uso da ferramenta. A partir da metodologia apresentada, foi possível levantar uma série de informações que ajudaram a atingir os objetivos específicos e responder a principal questão que permeia este trabalho, a qual foi destacada na introdução, sendo a seguinte: Como criar a estratégia (metodologia) para a implantação do sistema de gerenciamento na empresa estudada. 


\begin{abstract}
This paper presents a methodology for the implementation of the daily management system in the manufacturing of residential air conditioning cooling systems copper tubes process. The origin that motivated the development of this work stems from the observation by the researcher who saw that it was necessary to systematize the actions in order to guide any professional company through a visual management tool leveling the different levels of information for the process manufacturing. The study was conducted from a theoretical framework that formed the basis for the empirical development in the field. The main objective of this work is to present the tool model for further deployment. However, as of empirical analysis, it is believed that many benefits can be obtained with its implementation, which are presented in the study, among which the management of activities considered critical to achieving the company's strategic objectives. Finally it is concluded that this methodology will facilitate the work of those researchers or professionals who perchance have interest using the DMS tool.
\end{abstract}

Keywords: Management System; Daily Management System; Production Administration.

\title{
Referências
}

ANTUNES JUNIOR, J. A. V. Em Direção a uma Teoria Geral do Processo na Administração: uma discussão sobre a possibilidade de unificação da teoria das restrições e da teoria que sustenta a construção dos sistemas de produção com estoque zero. 1998. Tese (doutorado em Administração), Escola de Administração. Universidade Federal do Rio Grande do Sul. Porto Alegre.

CARVALHO, E.L.C. N. Implantação de um sistema de gestão por medidas de desempenho. 2003. Universidade Estadual de Campinas, Campinas.

CORRÊA, H. L.; CORRÊA, C.A. Administração de produção e operações, manufatura e serviços: uma abordagem estratégica. 2. ed. São Paulo: Atlas, 2006.

DENNIS, P.. Produção Lean Simplificada. Porto Alegre: Bookman, 2008.

DIEHL, A.L. Mudança de Layout para melhoria de produtividade no setor de costura em uma indústria calçadista. Dissertação de Mestrado, Mestrado Profissionalizante em Engenharia, Universidade Federal do Rio Grande do Sul, 2005.

DINIZ, M.V.; TÁVORA JÚNIOR, J.L. Avaliação da implementação do STP/TPM: estudo de caso em uma empresa multinacional. In: ENCONTRO NACIONAL DE ENGENHARIA DE PRODUÇÃO - ENEGEP, 24., 2004,

Florianópolis. Anais do XXIV ENCONTRO NACIONAL DE ENGENHARIA DE PRODUÇÃO. Florianópolis, 2004.

FUJIMOTO, T. The Evolution of Manufacturing System at Toyota. London:Oxford University Press, 1999

GHINATO, P. Sistema Toyota de Produção: mais do que simplesmente just-in-time, autonomação e zero defeitos. 1996. Dissertação (mestrado em Engenharia de Produção), Escola de Engenharia, Universidade Federal do Rio Grande do Sul, Caxias do Sul.

GHOBAD, C. Administração estratégica nas Organizações: o caso de uma empresa Monopsônica no Paraná. 2003. Dissertação (mestrado em Engenharia de Produção). Universidade Federal de Santa Catarina, Paraná.

HENDERSON, B.A.; LARCO, J.L. Lean Transformation: how to change your business into a lean enterprise. The Oaklea Press, 1999.

KOTLER, P.; KELLER, K.L. Administração de Marketing. 12 ed. São Paulo: Pearson Prentice Hall, 2006.

LIKER, J.K. O modelo Toyota: 14 princípios de gestão do maior fabricante do mundo. Porto Alegre: Bookman, 2005.

MOREIRA, D.A. Administração da produção e operações. 2. ed. São Paulo: Pioneira, 1996. 
MÜLleR, C.J. A Evolução dos Sistemas de Manufatura e a Necessidade de Mudanças nos Sistemas de Controle e Custeio. Porto Alegre, 1996. Dissertação (Mestrado em Engenharia de Produção), Escola de Engenharia. Universidade Federal do Rio Grande do Sul.

OHNO, T.: Toyota Production System: beyond large-scale production. Productivity Press, 1988.

OHNO, T. O Sistema Toyota de Produção: além da produção em larga escala. Porto Alegre: Bookman, 1997.

RAGO, S.F.T. et al. Atualidades na gestão da manufatura. São Paulo: IMAM, 2003.

REIS, A.C.C.. Implementação da manufatura enxuta na General Motors do Brasil: avaliação do "desdobramento" do plano de negócios na planta s-10. 2004. Dissertação (mestrado), Universidade de Taubaté, Taubaté.

SHINGO, S. O sistema Toyota de produção: do ponto de vista da engenharia de produção. 2. ed. Porto Alegre: Bookman, 1996.

SHINGO, S. O Sistema de Produção com estoque Zero: o sistema Shingo para melhorias contínuas. Porto Alegre: Bookman, 1996.

SLACK, N.et al. Administração da Produção. São Paulo: Atlas, 1997.

SLACK, N.; CHAMBERS, S.; JOHNSTON, R. Administração da Produção. São Paulo: Atlas, 2002.

SPEAR, S., BOWEN, H. B. Decodificando o DNA do Sistema Toyota de Produção. Harvard Business Review, pp.97106, September-October, 1999.

\section{Dados dos autores:}

Nome completo: Mychellangelo dos Santos Soares

Filiação institucional: Universidade Federal do Pará

Departamento: FT - Faculdade de Tecnologia

Função ou cargo ocupado: Mestrando em Mestrado Profissional em Engenharia de Processos Industriais

Endereço para correspondência: Cidade Universitária José da Silveira Neto - Rua Augusto Corrêa, 01 Guamá - Belém (PA) - CEP 66075-970 - Fone (91) 3201-7435 http://www.propesp.ufpa.br e-mail: mychellangelo@yahoo.com.br

\section{Nome completo: Tirso Lorenzo Reyes Carvajal}

Filiação institucional: Instituto de Tecnologia e Educação Galileo da Amazônia

Departamento: FT - Faculdade de Tecnologia

Função ou cargo ocupado: Orientador

Endereço para correspondência: Av. Joaquim Nabuco, 1950 - Centro, Manaus - AM, 69005-080

https://www.itegam.org.br/

e-mail: tirsolrca@gmail.com

Submissão: $16 / 11 / 2015$

Aceito: 06/03/2016 